\title{
Bilateral isokinetic variables of the shoulder: a prediction model for young men
}

\section{Raymond Chi-hung So MPhil, Oswald T. Siu Dr Sc*, Ming-kai Chin PhD, Kai-ming Chan MBBS FRCS(E) FRCS(G) M.Ch(ORTH) FRCS Ed(ORTH) ${ }^{\dagger}$}

Human Performance Laboratory, Sports Science Department, Hong Kong Sports Institute, *Statistical Consultation Services, City Polytechnic of Hong Kong and 'Department of Orthopaedics and Traumatology, The Chinese University of Hong Kong, Hong Kong

\begin{abstract}
Clinicians frequently want to know the pre-injury strength of an uninjured limb. The purpose of this study was to delineate the differences in bilateral isokinetic peak torque (PT) at $60 \%$ and $240 \%$, and torque acceleration energy (TAE), average power (AP) and total work (TW) at $240 \%$ during shoulder extension and flexion movements, and to develop a method to determine the expected maximal isokinetic variables of the dominant shoulder based upon isokinetic measurements from the non-dominant shoulder. Shoulder isokinetic meaurements were obtained from 30 normal young male adults. While bilateral correlation was significant $(P<0.01)$, results also suggest significant bilateral differences $P<0.01)$. Thus, it is inappropriate to use the uninjured extremity to predict the pre-injured strength of the injured side without adjustment. In this investigation models were developed relating the expected maximal isokinetic measurement of the dominant shoulder to the nondominant shoulder measurements.
\end{abstract}

Keywords: shoulder extension. shoulder flexion, isokinetics, prediction model

Clinicians traditionally predict pre-injury strength of an injured extremity using performance measurements of the corresponding uninjured extremity as a baseline. That is, the prescription of therapeutic exercises for rehabilitation is based on bilateral correspondence. However, the scientific assumption of this practice needs further clarification ${ }^{1,2}$. For example, Perrin et al. ${ }^{3}$ found that for shoulder extension (tested at 60 and $180 \%$ s), peak torque (PT) values were greater for the right than left side $(P<0.05)$ for non-athletes. This supposedly demonstrates that neuromotor dominance leads to a difference in PT for upper extremity measurements between the right and left sides of the body. On the other hand, the same investigator has not been able to find significant bilateral differences in the PT of the shoulder flexors. In fact, even the torque acceleration energy (TAE), total work (TW) and average power

Address for correspondence: Mr Raymond Chi-hung So MPhil, Sports Science Department, Hong Kong Sports Institute, Shatin, N.T., Hong Kong
(AP) measurements of shoulder extensors and flexors revealed no significant bilateral difference.

Further confusion in the literature abounds. Otis ${ }^{4}$ demonstrated that bilateral differences exist in shoulder flexion torque during isometric contractions at $0^{\circ}$ and $90^{\circ}$, with the dominant shoulder producing greater torque than the non-dominant side. On the other hand, Connelly Maddux $x^{5}$ found no significant difference in the isokinetic PT produced by an individual's dominant and non-dominant shoulder musculature, although the TAE measure did suggest bilateral differences. Ivey et al. ${ }^{6}$ reported no significant difference between dominant and non-dominant peak isokinetic torque at $60^{\circ}$ and $180^{\circ} /$ s. Hinton et al. ${ }^{7}$ stated that the pitching shoulder internal rotators produced significantly higher isokinetic PT values, PT to body weight ratio measured at $60^{\circ}$ and $180^{\circ} / \mathrm{s}$, and TW values measured at $240 \%$ s. Brown et al. ${ }^{8}$ found significantly greater isokinetic torque produced by the dominant arm in comparison with the non-dominant arm for both pitchers and position players at all testing speeds $\left(180^{\circ}, 240^{\circ}\right.$ and $\left.300^{\circ} / \mathrm{s}\right)$ in the movement of shoulder internal and external rotation.

We thus conducted this study to: (1) examine differences in bilateral isokinetic muscular characteristics during shoulder extension and flexion; and (2) to suggest simple statistical models for relating the expected maximal isokinetic measurements of the dominant (often the injured side) shoulder to the non-dominant shoulder measurements.

\section{Materials and methods}

The subjects comprised 30 normal, healthy males whose mean(s.d.) age was 21(2.3) years, height was $167.9(4.4) \mathrm{cm}$, and weight was $59.1(7.3) \mathrm{kg}$. The dominant side was identified as the side used for handwriting. None of the subjects had shoulder pain or injury at the time of the study. Subjects came responding to our call for volunteers among postsecondary institutions and gave their written consent to participate.

Bilateral isokinetic measures were measured with a Cybex II+ isokinetic dynamometer (Cybex, Ronkokoma, NY, USA) equipped with an upper body exercise 
and testing table (UBXT). The Cybex II+ dual channel recorder and dynamometer were interfaced with the Cybex Data Reduction Computer (CDRC) for analysis of tests results. Studies by Moffroid et al. ${ }^{9}$, Bemben et al. ${ }^{10}$, Montgomery et al..$^{11}$, Magnusson et al. ${ }^{12}$, Johnson and Siegal ${ }^{13}$ and Kuhlman et al. ${ }^{2}$ support the reliability and validity of isokinetic extremities tests performed on Cybex machines. Each subject underwent isokinetic testing for the right and left shoulder extensor and flexor muscle groups. Subjects were stabilized with straps during testing, and the joint's axis of rotation was aligned with the input shaft of the dynamometer. To provide gravity correction during shoulder testing, the gravitational movement of the Cybex arm, shank and the arm were determined by the CDRC. A damp setting of three was used throughout the testing. The dynamometer was calibrated at the beginning of each testing session. Shoulder extension and flexion tests were assessed with subjects in the supine position.

After setting the apparatus for the appropriate joint, according to the Cybex isolated joint testing manual ${ }^{14}$, the subject underwent a warm-up session at $60 \%$. Warm up consisted of three submaximal and two maximal contractions followed by a $30 \mathrm{~s}$ rest period prior to testing. Testing at $60 \%$ included five maximal repetitions, and testing at $240 \%$ included 25 maximal repetitions. One minute rest was allowed between tests at $60 \%$ s and $240 \% \mathrm{~s}$, and a $10 \mathrm{~min}$ rest period was allowed prior to the contralateral side testing. A period of $30 \mathrm{~min}$ was allowed between the two shoulder movements. In all cases, the low speed and non-dominant side was tested first and the order of testing for the two muscles groups was determined by random selection.

The muscular isokinetic characteristics investigated included: (1) PT, a measurement of muscle strength, the single highest torque output of the joint produced by muscular contraction as the limb moves through the range of motion (unit: $\mathrm{Nm}$ ); (2) TW is derived by multiplying torque by the distance of the total area under the torque curves over a preselected number of repetitions. It is a measurement of muscle absolute endurance. TW analysis measures muscle function in every repetition at all points in the range of motion, while PT analysis only reports muscle function at one point (unit:W); (3) AP, the TW of the given contractions divided by the time taken to complete the motion (unit:W); (4) peak TAE, is a measurement of the peak power (explosive power) of the muscle involved, the greatest amount of work done in the first one-eighth of a second of a single torque production in test repetitions. It is an indication of the rate at which motor unit fibre recruitment take place (unit:J).

PT measurements were obtained at both testing speeds. TAE, AP and TW measurements were obtained during the 25 repetitions work test at the high speed of contractions. All isokinetic measurements were obtained during one test session in a laboratory control environment.

Student's paired $t$ tests were used to test all isokinetic measurements for bilateral differences with a level of significance set at two-tailed $P<0.01$. Correlation was used to determine the linear relationship between dominant and non-dominant results for the same measurement. Moreover, correlation was used to assess the linear relationship between all measurements produced in each movement test with a significance level set at one-tailed $P<0.01$. A prediction model was developed via stepwise multiple regression. SPSS/PC + Version $3.0^{15}$ was used to perform all the required calculations.

\section{Results}

Tables 1 and 2 list the means(s.d.) and correlation coefficients of the isokinetic measurements for the dominant and non-dominant side. Dominant and non-dominant sides isokinetic results were statistically different for all measurements of shoulder extension and flexion $(P<0.01)$. Statistically significant correlations were found for all measurements.

Tables 3 and 4 list the correlation coefficients for the isokinetic movements of the dominant shoulder. Tables 5 and 6 list the corresponding coefficients for the non-dominant shoulder. High correlations were found throughout. Therefore, two measurements with the least correlation coefficient from the nondominant shoulder were chosen to do the multiple regression test and build up the model for predicting the performance of the dominant shoulder in each of the movement tests. Consequently, TAE and TW measurements were chosen for the shoulder extension movement test PT at $60 \%$ and AP measurements were chosen for the shoulder flexion test.

Table 1. Mean and standard deviation for isokinetic measures for 30 subjects, paired $t$ test value and correlation coefficients, both with significant levels for the bilateral analysis

\begin{tabular}{|c|c|c|c|c|c|c|c|}
\hline \multirow[b]{3}{*}{ Testing speed $(\% / s)$} & \multirow[b]{3}{*}{ Measures } & \multicolumn{2}{|c|}{ Shoulder extension } & \multirow[b]{3}{*}{ t value } & \multirow[b]{3}{*}{$\mathbf{P}$} & \multirow{3}{*}{$\begin{array}{l}\text { Correlation } \\
\text { coefficient }\end{array}$} & \multirow[b]{3}{*}{$\mathbf{P}$} \\
\hline & & Dominant & Non-dominant & & & & \\
\hline & & $x(s . d)$. & $x($ s.d.) & & & & \\
\hline 60 & Peak torque $(\mathrm{Nm})$ & 66.7(12.9) & $60.1(13.9)$ & -4.73 & $\mathbf{S}$ & 0.838 & $\mathrm{~S}$ \\
\hline 240 & Peak torque (Nm) & 44.5(10.2) & 37.5(10.9) & -6.17 & S & 0.827 & $\mathrm{~S}$ \\
\hline 240 & TAE (J) & $18.22(4.07)$ & $15.68(4.08)$ & -4.58 & $\mathbf{S}$ & 0.723 & $\mathbf{S}$ \\
\hline 240 & TW (J) & 1265.9(391.2) & 1037.3(351.2) & -5.59 & $\mathbf{S}$ & 0.823 & $\mathbf{S}$ \\
\hline 240 & $\mathrm{AP}(\mathrm{W})$ & $84.3(27.8)$ & $70.1(25.4)$ & -5.58 & $\mathbf{S}$ & 0.867 & $\mathbf{S}$ \\
\hline
\end{tabular}

NS, not significant $(P>0.05) ; S$, significant $(P<0.05)$; AP, average power; TW total work; TAE, torque acceleration energy 
Bilateral isokinetic variables of the shoulder: a prediction model for young men: $R$. Chi-hung So et al.

Table 2. Mean(s.d.) isokinetic measures for 30 subjects, paired $t$ test value and correlation coefficients, both with significant levels for the bilateral analysis

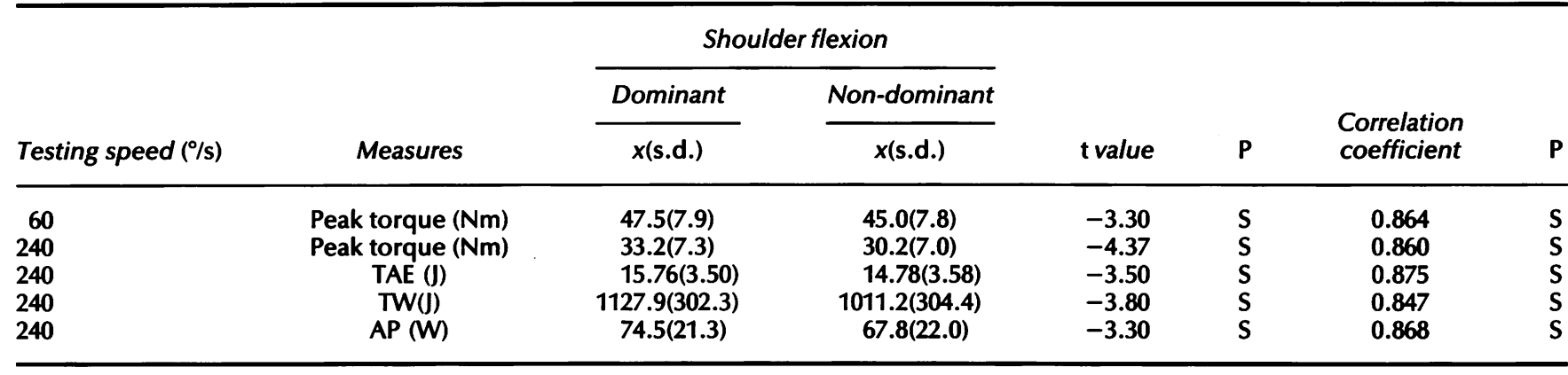

NS, not significant $(P>0.05) ; S$, significant $(P<0.05)$; AP, average power; TW, total work; TAE, torque acceleration energy

Table 3. Correlation matrix of isokinetic measures for the dominant shoulder in shoulder extension movement test

\begin{tabular}{lccccc}
\hline & Peak torque $\left(60^{\circ} / \mathrm{s}\right)$ & Peak torque $\left(240^{\circ} / \mathrm{s}\right)$ & TAE $\left(240^{\circ} / \mathrm{s}\right)$ & $T W\left(240^{\circ} / \mathrm{s}\right)$ & AP $\left(240^{\circ} / \mathrm{s}\right)$ \\
\hline Peak torque $\left(60^{\circ} / \mathrm{s}\right)$ & 1.000 & 0.763 & 0.819 & 0.619 & 0.616 \\
Peak torque $\left(240^{\circ} / \mathrm{s}\right)$ & 0.763 & 1.000 & 0.888 & 0.896 & 0.899 \\
TAE $\left(240^{\circ} / \mathrm{s}\right)$ & 0.819 & 0.888 & 1.000 & 0.738 \\
TW $\left(240^{\circ} / \mathrm{s}\right)$ & 0.619 & 0.896 & 0.777 & 0.986 & 1.000 \\
AP $\left(240^{\circ} / \mathrm{s}\right)$ & 0.616 & 0.899 & 0.738 & 0.986 & 1.000 \\
\hline
\end{tabular}

$A P$, average power; TW, total work; TAE, torque acceleration energy

Table 4. Correlation matrix of isokinetic measures for the dominant shoulder in shoulder flexion movement test

\begin{tabular}{lcccrr}
\hline & Peak torque $\left(60^{\circ} / \mathrm{s}\right)$ & Peak torque $\left(240^{\circ} / \mathrm{s}\right)$ & TAE $\left(240^{\circ} / \mathrm{s}\right)$ & TW $\left(240^{\circ} / \mathrm{s}\right)$ & AP $\left(240^{\circ} / \mathrm{s}\right)$ \\
\hline Peak torque $\left(60^{\circ} / \mathrm{s}\right)$ & 1.000 & 0.824 & 0.729 & 0.758 & 0.744 \\
Peak torque $\left(240^{\circ} / \mathrm{s}\right)$ & 0.824 & 1.000 & 0.841 & 0.866 & 0.873 \\
TAE $\left(240^{\circ} / \mathrm{s}\right)$ & 0.729 & 0.841 & 1.000 & 0.825 & 0.808 \\
TW $\left(240^{\circ} / \mathrm{s}\right)$ & 0.758 & 0.866 & 0.825 & 1.000 & 0.983 \\
AP $\left(240^{\circ} / \mathrm{s}\right)$ & 0.744 & 0.873 & 0.808 & 0.983 & 1.000 \\
\hline
\end{tabular}

AP, Average power; TW, total work; TAE torque acceleration energy

Table 5. Correlation matrix of isokinetic measures for the non-dominant shoulder in shoulder extension movement test

\begin{tabular}{lccccc}
\hline & Peak torque $\left(60^{\circ} / \mathrm{s}\right)$ & Peak torque $\left(240^{\circ} / \mathrm{s}\right)$ & TAE $\left(240^{\circ} / \mathrm{s}\right)$ & TW $\left(240^{\circ} / \mathrm{s}\right)$ & AP $\left(240^{\circ} / \mathrm{s}\right)$ \\
\hline Peak torque $\left(60^{\circ} / \mathrm{s}\right)$ & 1.000 & 0.888 & 0.838 & 0.836 & 0.838 \\
Peak torque $\left(240^{\circ} / \mathrm{s}\right)$ & 0.888 & 1.000 & 0.932 & 0.916 & 0.927 \\
TAE $\left(240^{\circ} / \mathrm{s}\right)$ & 0.838 & 0.932 & 1.000 & 0.836 & 0.851 \\
TW $\left(240^{\circ} / \mathrm{s}\right)$ & 0.836 & 0.916 & 0.836 & 1.000 & 0.984 \\
AP $(240 \%)$ & 0.838 & 0.927 & 0.851 & 0.984 & 1.000 \\
\hline
\end{tabular}

$A P$, average power; TW, total work; TAE, torque acceleration energy

Table 6. Correlation matrix of isokinetic measures for the non-dominant shoulder in shoulder flexion movement test

\begin{tabular}{|c|c|c|c|c|c|}
\hline & Peak torque $\left(60^{\circ} / \mathrm{s}\right)$ & Peak torque $\left(240^{\circ} / \mathrm{s}\right)$ & $\operatorname{TAE}\left(240^{\circ} / \mathrm{s}\right)$ & $T W\left(240^{\circ} / \mathrm{s}\right)$ & $A P\left(240^{\circ} / s\right)$ \\
\hline $\begin{array}{l}\text { Peak torque }\left(60^{\circ} / \mathrm{s}\right) \\
\text { Peak torque }\left(240^{\circ} / \mathrm{s}\right) \\
\text { TAE }\left(240^{\circ} / \mathrm{s}\right) \\
\text { TW }\left(240^{\circ} / \mathrm{s}\right) \\
\text { AP }\left(240^{\circ} / \mathrm{s}\right)\end{array}$ & $\begin{array}{l}1.000 \\
0.771 \\
0.775 \\
0.683 \\
0.667\end{array}$ & $\begin{array}{l}0.771 \\
1.000 \\
0.940 \\
0.876 \\
0.883\end{array}$ & $\begin{array}{l}0.775 \\
0.940 \\
1.000 \\
0.872 \\
0.881\end{array}$ & $\begin{array}{l}0.683 \\
0.876 \\
0.872 \\
1.000 \\
0.978\end{array}$ & $\begin{array}{l}0.667 \\
0.883 \\
0.881 \\
0.978 \\
1.000\end{array}$ \\
\hline
\end{tabular}

$A P$, average power; TW, total work; TAE, torque acceleration energy 
Table 7. $r^{2}$ results (stepwise multiple regression) of each measure of dominant shoulder in the shoulder extension movement test

\begin{tabular}{lccc}
\hline $\begin{array}{l}\text { Dependent } \\
\text { variables } \\
\text { (dominant } \\
\text { shoulder) }\end{array}$ & $\begin{array}{c}\text { Independent } \\
\text { variables } \\
\text { (non-dominant } \\
\text { shoulder) }\end{array}$ & $\mathbf{r}^{2}$ & $\begin{array}{c}\text { Variables in } \\
\text { the equation }\end{array}$ \\
\hline Peak torque $(60 \% / \mathrm{s})$ & TAE, TW & 0.7885 & TAE \\
Peak torque $(240 \%)$ & TAE, TW & 0.8052 & TAE \\
TAE $(240 \%)$ & TAE, TW & 0.7230 & TAE \\
TW $(240 \%)$ & TAE, TW & 0.8229 & TW \\
AP $(240 \%)$ & TAE, TW & 0.8413 & TW \\
\hline
\end{tabular}

$A P$, average power; TW, total work; TAE, torque acceleration energy

Tables 7 and 8 list the $r^{2}$ (stepwise multiple regression) values for each measurement in the two dominant shoulder movement tests. The measurment with the highest $r^{2}$ value was selected as the representative model for that particular movement test.

Two different models (Table 9) were developed, by using stepwise multiple regression, to predict the dominant shoulder AP measurement in the shoulder extension test and TW measurement in the shoulder flexion test. Non-dominant side TW measurement was the sole factor in the model for predicting the dominant side PT measurement in the shoulder extension test. In addition to AP measurement, PT at $60 \%$ were also factors involved in the shoulder flexion test model.

The $r^{2}$ (coefficient of determination calculated from linear regression method) indicates how well the equation fits the population. The average $r^{2}$ value for the two models was measured 0.863 out of unity.

For example, a 20 -year-old male who is just starting a rehabilitation programme for a deficit of the dominant shoulder firstly performs a Cybex muscular test on both shoulders with the movement of shoulder extension and flexion according to the standard protocol. The testing results of the uninvolved shoulder (non-dominant side) can be used to calculate the AP of the involved shoulder (dominant side) in shoulder extension movement tests by using the listed models (Table 9). If the TW measurement of the shoulder extension movement was $1100 \mathrm{~J}$ for the non-dominant side, and $40 \mathrm{~W}$ for the dominant side AP measurements, the calculations can be shown as follows:

predicted AP of the dominant shoulder in extension movement: $0.067^{*}(1100)+15.27=88.97$
Table 9. Statistical models for determining the expected measures of dominant shoulder from non-dominant shoulder measures

\begin{tabular}{|c|c|c|c|}
\hline $\begin{array}{l}\text { Shoulder } \\
\text { movement }\end{array}$ & $\begin{array}{l}\text { Expected measures } \\
\text { (dominant shoulder) }\end{array}$ & Model & $r^{2}$ \\
\hline $\begin{array}{l}\text { Extension } \\
\text { Flexion }\end{array}$ & $\begin{array}{l}\text { AP } \\
\text { TW }\end{array}$ & $\begin{array}{c}0.07^{*}(\mathrm{TW})+15.27 \\
8.80^{*}(\mathrm{AP})+12.41 \\
\left(\mathrm{PT} \text { at } 60^{\circ} / \mathrm{s}\right)-27.62\end{array}$ & $\begin{array}{l}0.841 \\
0.885\end{array}$ \\
\hline
\end{tabular}

AP, average power; PT, peak torque; TW, total work

In this way, the clinician can predict pre-injury strength of an injured dominant limb, both extension and flexion. When a dominant shoulder result is far from the predicted value, it is reasonable to conclude that the shoulder is exhibiting muscular weakness or has not fully recovered.

\section{Discussion}

The findings of this study confirmed to a certain extent the conclusion made by Cahalan et al. ${ }^{1}$ and Perrin $e t a l^{2}$ in that they questioned the efficacy of assuming bilateral equivalence for PT, TAE, AP and TW measurements in the prescription of therapeutic exercise for all muscle groups in all athletic and non-athletic populations. All the tested measurements in the two movement tests revealed significant bilateral differences. Therefore, it seems inappropriate to use the uninjured shoulder to predict the pre-injured strength of the injured side without proper adjustment.

The models developed in this investigation can be used to predict the pre-injury muscular characteristics of the injured shoulder. Moreover, by calculation and comparison, the deficit muscle groups (shoulder extensors or flexors) can be identified. For example, if the dominant shoulder extensors' AP measurement was below the predicted value, a strength rehabilitation programme for the involved shoulder extensors could be involved in the rehabilitation programme.

These equations will provide the clinician with subjective information about the involved shoulder muscle. In addition, Cybex testing is a good method to evaluate the progress of the rehabilitation programme. Clearly, an improvement on the predicted mean for the involved shoulder would reflect a desirable outcome. Rehabilitation should continue until maximal recovery is achieved and the predicted value should be used to provide a reference for

Table 8. $r^{2}$ results (stepwise multiple regression) of each measure of dominant shoulder in the shoulder flexion movement test

\begin{tabular}{|c|c|c|c|}
\hline Dependent variables (dominant shoulder) & Independent variables (non-dominant shoulder) & $r^{2}$ & Variables in the equation \\
\hline $\begin{array}{l}\text { Peak torque }(60 \%) \\
\text { Peak torque }(240 \% / s) \\
\text { TAE }(240 \% / s) \\
\text { TW }(240 \%) \\
\text { AP }(240 \%)\end{array}$ & $\begin{array}{l}\text { Peak torque }(60 \%) \text {, AP } \\
\text { Peak torque }(60 \% / \mathrm{s}) \text {, AP } \\
\text { Peak torque }(60 \%) \text {, AP } \\
\text { Peak torque }(60 \%) \text {, AP } \\
\text { Peak torque }(60 \%) \text {, AP }\end{array}$ & $\begin{array}{l}0.8641 \\
0.8599 \\
0.7565 \\
0.8853 \\
0.8682\end{array}$ & $\begin{array}{l}\text { Peak torque }\left(60^{\circ} / \mathrm{s}\right) \\
\text { Peak torque }\left(60^{\circ} / \mathrm{s}\right) \text {, AP } \\
\text { AP } \\
\text { Peak torque }\left(60^{\circ} / \mathrm{s}\right) \text {, AP } \\
\text { Peak torque }\left(60^{\circ} / \mathrm{s}\right) \text {, AP }\end{array}$ \\
\hline
\end{tabular}

AP, average power; TW, total work; TAE, torque acceleration energy 
In this study, normative values for PT, TAE, AP and TW, taken from the movement testing of shoulder extension and flexion, were presented. The shoulder extension PT for both dominant and non-dominant sides were comparatively lower than the results reported by Perrin ${ }^{3}$ (dominant side: $86 \mathrm{Nm}$ and non-dominant side: $82 \mathrm{Nm}$ ).

The inconsistency between the upper extremity bilateral difference and muscle strength might be due to the population being tested. Therefore, it should be noted that the results in this study were gathered from young, non-athletic, healthy Chinese male adults. The model presented in this study may not be applicable to other racial groups, age groups, female or élite athletes. More study should be done on these populations in order to determine the bilateral relationships for different population groups.

We have presented some normative isokinetic values for shoulder extension and flexion measurements in this report. Dominant side results were shown as significantly higher than the non-dominant side, and models were developed to predict normative isokinetic parameter values for the dominant side based on measurements from the non-dominant shoulder.

\section{References}

1 Cahalan TD, Johnson ME, Chao EYS. Shoulder strength analysing using the Cybex II isokinetic dynamometer. Clin Orth Rel Res 1991; 271: 249-57.

2 Kuhlman JR, Iannotti JP, Kelly MJ, Riegler FX, Gevaert ML,
Ergin TM. Isokinetic and isometric measurement of strength of external rotation and abduction of the shoulder. J Bone Joint Surg 1992; 74-A: 1320-33.

3 Perrin DH, Robertson RJ, Ray RL. Bilateral isokinetic peak torque, torque acceleration energy, power, and work relationships in athletes and nonathletes. J Ortho Sports Phys Ther 1987; 9: 184-9.

4 Otis JC, Warren RF, Backus SI, Santner TJ, Mabrey JD. Torque production in the shoulder of the normal young adult male. Am J Sports Med 1990; 18: 119-23.

5 Connelly Maddux RE, Kibler WB, Uhl T. Isokinetic peak torque and work values for the shoulder. J Ortho Sports Phys Ther 1989; 10: 264-9.

6 Ivey FM, Calhoun JH. Isokinetic testing of shoulder strength: normal values. Arch Phys Med Rehab 1985; 66: 384-6.

7 Hinton RY. Isokinetic evaluation of shoulder rotational strength in high school baseball pitchers. Am J Sports Med 1988; 16: 274-9.

8 Brown LP, Niehues SL, Harrah A, Yavorsky P, Hirshman HP. Upper extremity range of motion and isokinetic strength of the internal and external shoulder rotators in major league baseball players. Am J Sports Med 1988; 16: 577-85.

9 Moffroid M, Whipple R, Hofkosh J, Lowman W. Thistle H. A study of isokinetic exercise. Phy Ther 1969; 49: 735-46.

10 Bemben MG, Grump KJ, Massey BH. Assessment of technical accuracy of the Cybex II isokinetic dynamometer and analog recording system. J Ortho Sports Phys Ther 1988; 7: 12-17.

11 Montgomery LC, Douglass LW, Deuster PA. Reliability of an isokinetic test of muscle strength and endurance. $J$ Ortho Sports Phys Ther 1989; 10: 315-22.

12 Magnusson SP, Gleim GW, Nicholas JA. Subject variability of shoulder abduction strength testing. Am J Sports Med 1990; 18: 349-53.

13 Johnson J, Siegal D. Reliability of an isokinetic movement of the knee extension. Res Quar Exer Sports 1988; 49: 88-90

14 Cybex. Isolated-Joint Testing and Exercise. Ronkohoma, NY, USA: Cybex. 1983.

15 SPSS PC + Ver. 3.0 Chicago, Illinois, USA: SPSS Inc 1989. 